\title{
Towards an aquatic mammal research code of conduct in Latin America: Ethical before technical considerations
}

\author{
Fernando Félix ${ }^{1,2, *}$ and Koen Van Waerebeek ${ }^{3,4,5}$ \\ ${ }^{1}$ Pontificia Universidad Católica del Ecuador (PUCE), Avenida 12 de Octubre 1076, Quito, Ecuador \\ ${ }^{2}$ Museo de Ballenas, Avenida Enríquez Gallo s/n, Salinas, Ecuador \\ ${ }^{3}$ Centro Peruano de Estudios Cetológicos (CEPEC), Museo de Delfines, calle Jorge Chávez 302, Lima 20, Peru \\ ${ }^{4}$ Centre for Marine Mammals Research Leviathan (CMMR), CP 7640392, Santiago, Chile \\ ${ }^{5}$ Life Education and Chinese White Dolphin Research and Conservation Center of Beibu Gulf, \\ Sanniang Bay Village 345, Qinnan District, Qinzhou, Guangxi, China \\ *Corresponding author: fefelix90@gmail.com
}

\section{Introduction}

Aquatic mammal research demands a vast effort in terms of human and financial resources due to the technical difficulties inherent in working with highly mobile animals living in open waters and that remain underwater for extended periods. The use of vessels and aircraft to track and study animals that often reproduce or feed in remote locations are examples of research that demand complex logistics and incur high operating costs. Added to this is the potential danger posed to research teams by working often under extreme environmental conditions. The need to overcome these limitations and improve our knowledge about the role of aquatic mammals in marine and freshwater ecosystems, and how human activities are affecting the natural balance, has promoted the development of new research disciplines and enhanced the use of new technologies in the field (e.g. Block et al., 2011; Gonzalez-Socoloske and Olivera-Gomez, 2012; Mclntyre, 2014; Nowacek et al., 2016; Hastie et al., 2019). Some may have mostly negligible impact, such as the use of unmanned aerial vehicles (UAVs) and underwater photography to study cetaceans (Christiansen et al., 2016; Nowacek et al.,

\section{ARTICLE INFO \\ Manuscript type: Opinion \\ Article History \\ Received: 30 April 2021 \\ Received in revised form: 22 May 2021 \\ Accepted: 02 June 2021 \\ Available online: 25 August 2021}

Responsible Editor: Miriam Marmontel

Citation:

Félix, F. and Van Waerebeek, K. (2021) Towards an aquatic mammal research code of conduct in Latin America: Ethical before technical considerations. Latin American Journal of Aquatic Mammals 16(1): 61-65. https://doi.org/10.5597/lajam00274
2016; Van Bressem et al., 2018; García-Cegarra et al., 2021), but others such as tagging operations may provoke considerable impact, e.g. cause broad swellings and focal lesions (Robbins et al., 2013), or have unknown long-term consequences. The rapid deterioration of some wild populations, particularly aquatic megafauna, may put significant pressure on researchers and managers who seek to understand the causes and try, in great haste, to implement short-term solutions in an attempt to stop population decline. These tend to be ineffective, may overlook animal welfare issues, potentially create new complications in the longer term, or even lead to a literal dead-end. The fast decline of the baiji Lipotes vexillifer in the Yangtze River, China (Wang et al., 2006) and the predictable, failed attempt to captive-breed the species when the last of five animals under human care died in 2002 (Zhang et al., 2012), are tragic examples.

Certain scientific societies which deal with aquatic mammal research, such as the US-based Society for Marine Mammalogy, have developed a "Code of Professional Ethics". The latter primarily formulates practical guidelines about the ethical aspects of conducting scientific research, the interaction with colleagues and associates, as well as ethical issues related to the publication process ${ }^{1}$. Its members are expected to take these into account when preparing research proposals and to implement them rigorously during field and experimentation phases. However, animal welfare issues are only briefly and indirectly addressed. The $15^{\text {th }}$ guiding principle states: "Adhere to the highest standards for treatment of animals used in research in a way that contributes positively to sustaining natural populations and ecosystems."

The Latin American Society for Experts of Aquatic Mammals ${ }^{2}$ or Sociedad Latinoamericana de Especialistas en Mamíferos Acuáticos (SOLAMAC) does not yet have an official code of conduct. The authors, both steering members of the society's Ethics Committee, undertook to draft a number of basic recommendations that would hopefully muster a wide consensus among members and the directorate, and if not, at least generate a constructive discussion. 


\section{Major ethic issues concerning marine mammal research}

\section{Animal welfare}

There often exists a tendency to apply invasive methodologies that offer to solve many of the limitations associated with aquatic mammal research by remote monitoring. However, in a blind rush for scientific data, aspects of animal welfare may be overlooked, such as indiscriminate biopsy darting or deploying tracking devices that may cause pain, serious injuries, increase stress, needlessly predispose animals to diseases, increase the risk of predation, or modify their social behavior (e.g. Walker et al., 2012; Robbins et al., 2013; Macfarlane, 2015; Papastavrou et al., 2017). Papastavrou et al. (2017) convincingly demonstrated, and we concur, why management decisions involving marine mammals should include animal welfare. They describe how an attitude that only takes into account population-level effects, while consistent with the value-based nature of conservation generally, is at odds with current scientific evidence (e.g. Whitehead et al., 2004; 2017; Félix, 2021). There is a clear scientific basis for managing human activities not only to sustain populations, but also to minimize welfare impacts on individual animals. This view is increasingly consistent with evolving societal values, now reflected in an array of legal regimes reflecting public concern for welfare of individual animals (Papastavrou et al., 2017).

Guidelines for tagging cetaceans have recently been developed in the framework of the International Whaling Commission (IWC) (Andrews et al., 2019). These technical guidelines relate to "scientifically valid and acceptable approaches to the handling and treatment of aquatic mammals during field research, following ethical standards accepted by the international scientific community". Nonetheless we recommend that in view of potential severe health impacts, as mentioned, the absolute necessity of tagging should be carefully assessed, particularly in the case of small cetaceans, considering non-invasive alternatives and that the research is essential for the effective management of the population or species involved.

Live captures

A recent live-capture experiment of vaquitas Phocoena sinus in the Gulf of California, with the intention of biological sampling and ex-situ captive breeding in a no doubt well-meaning, but misguided, attempt to save the most threatened living cetacean species with a total population estimated at less than 19 individuals (Jaramillo-Legorreta et al., 2019), is of serious concern. The resounding failure of this initiative that ended with the death of two animals before it was aborted, leads us to reflect on whether there was an in-depth risk-benefit analysis before undertaking such levels of intervention. The critical state of a species or population demands a far more rigorous assessment framework and higher standards than those used under more favorable population conditions. This demonstrates how complex and dynamic an ethical framework must be to deal with aspects that cannot always be foreseen in legislation or scientific protocols.

Another good example concerns the Atlantic humpback dolphin Sousa teuszii, endemic to western and central Africa and subject to severe fisheries pressures including direct exploitation (Van Waerebeek et al., 2004; 2017; Weir et al., 2011). Considering that the species is potentially 'Critically Endangered' (Collins, 2015), it would be technically misguided and ethically indefensible to subject it to risky live-capture attempts for biological sampling or experimenting in the name of serving a future ex-situ conservation strategy. And yet this is precisely what is envisioned by some interest groups. Ample literature is available on the general biology of the closely related Indo-Pacific humpback dolphin Sousa chinensis (reviews e.g. Wilson et al., 2008; Pan et al., 2013; Jefferson and Curry, 2016) and practical husbandry expertise exists with rehabilitated or otherwise captive S. chinensis in Asian aquaria (Figs. 1 and 2). This knowledge, if necessary, could be collated and applied for any perceived need of a $S$. teuszii rehabilitation strategy, which may not even be a realistic scenario as not a single case of a $S$. teuszii individual requiring rehabilitation has ever been reported. The species faces other severe challenges that will need a dramatic change in management approach and some brave decisions. However, we believe that ex-situ conservation is not a realistic solution for $S$. teuszii and not a message international scientists should convey to range state authorities. Finding a balance between the potential benefit of obtaining new information with one technique or another and real, arguably unacceptable, risks incurred for

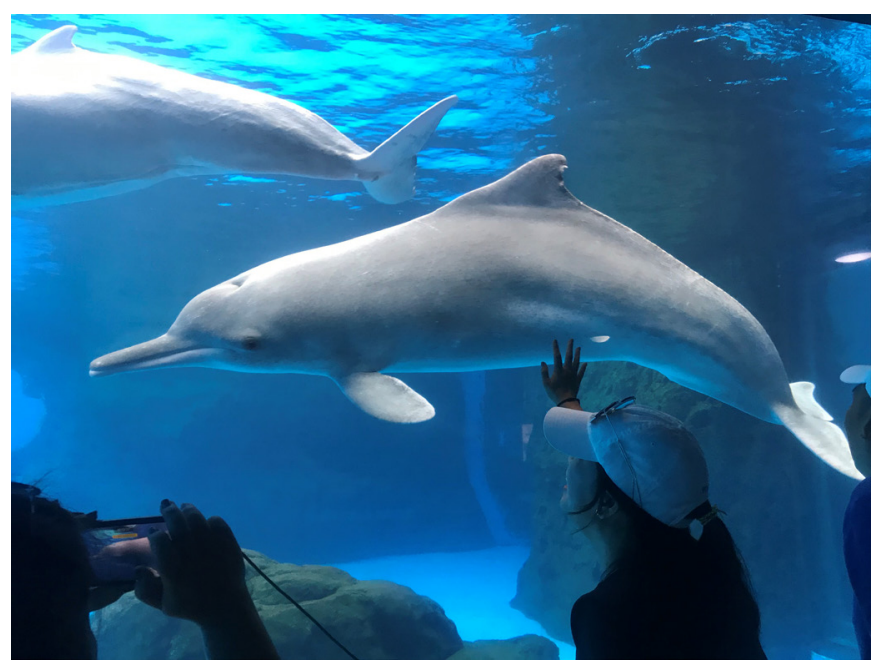

Figure 1. Two Indo-Pacific humpback dolphins Sousa chinensis, an adult female (left) and a juvenile male (center), displayed at Chang Long Ocean Park Zhuhai, Guangdong, China, 28 September 2019. Reportedly originating from Thailand, the juvenile was born but not conceived in captivity. Knowledge of health aspects, physiology and husbandry of this species can be used as a proxy for the closely related, endangered Atlantic humpback dolphin S. teuszii (Photo: KVW).

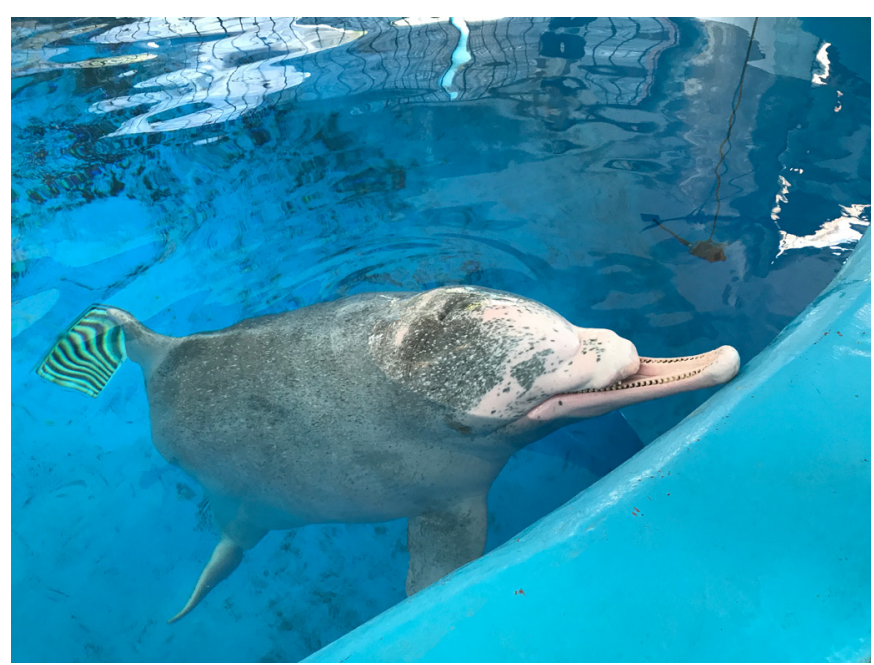

Figure 2. Adult Sousa chinensis rehabilitated at the Nanning Zoo (Nanning, China) after suspected propeller strike caused it to strand in Beihai Bay, Beibu Gulf, in August 2007 (photo courtesy Hong Yu Lai). 
individual animals, and thus also for the endangered species, is something that researchers and managers must seriously assess (Macfarlane, 2015). In this process, the precautionary principle should be the predominant criterium at all decision levels.

In April 2021, several NGOs started a campaign directed to the Norwegian Food and Safety Authority (Mattilsynet), requesting to revoke the permit to conduct an invasive auditory evoked potential (AEP) study on the effect of loud noises such as from naval sonar and seismic surveying on the brain waves of common minke whales (Balaenoptera acutorostrata). The study requires the capture of up to 12 juvenile whales to hold them captive for several days in an ocean pen at Lofoten, Norway. Sedation and even stunning the whales that will likely panic when feeling trapped is being considered in "emergency situations". Some 54 whale scientists have warned the Norwegian authorities about the risks for both whales and researchers who will conduct the experiment due to the unpredictable behavior of severely distressed whales. It is not clear what kind of interests this type of research responds to. Also, ethical and animal welfare aspects have clearly not been taken into account. Moreover, the waste of resources in such meaningless research offends the scientific community in developing countries working with limited funds on true conservation issues. Indeed, observational studies have already demonstrated how baleen whales react to very loud anthropogenic noises; they stay away or flee (e.g. Richardson and Würsig, 1997; Richardson et al., 1999; Erbe et al., 2018; Boisseau et al., 2021).

\section{Animal rights}

The importance for cetacean population management in assessing proposals for invasive sampling must also take into account behavioral, social and animal-cultural aspects highlighted in certain cetacean species since they constitute part of the evolutionary legacy of these complex animal societies (Whitehead et al., 2004). The trend in the world to grant legal status to animals is growing (Papastavrou et al., 2018) and this should lead researchers to reflect on the level of intervention when invasive methodologies or captive strategies are proposed. The Constitution of Ecuador (2008), for example, recognizes in its Article 10 that nature is subject to rights, and includes an entire chapter (No. 7) and four articles on this issue.

The German Constitution in its Article 20a (2002) establishes that the State will protect the natural foundations of life and animals. The US Animal Welfare Act signed into law in 1966 mandates the establishment, at each animal research institution, of an institutional animal care and use committee (IACUC) that must review all proposed animal research protocols and ensure that the researchers make efforts to treat the animals humanely. While invasive techniques are listed among possible non-lethal techniques such as the deployment of satellite or acoustic devices on the body of an animal, and the extraction of blubber and tissue when biopsying for genetics, physiological and contaminants studies, they should not be abused. There are other non-biological considerations beyond conservation and strict animal welfare to bear in mind when incorporating these methodologies in research programs, including those related to the moral and legal rights of non-human species that demand care and respect.

\section{Case study: SOLAMAC}

Although the ethical guidelines of any professional society provide a general framework that is expected to enlighten the behavior of its members, it is necessary to highlight the fact that these of course remain of voluntary application, and restricted to these societies. There is no way to ensure these principles are being complied with or even to know to what extent these ethical guidelines are effective in practice unless a follow-up can be made. Thus, the responsibility for monitoring its implementation extends to other intermediaries of scientific work, including ethics committees that evaluate methodologies of project proposals, sponsors that finance research, national authorities that issue permits, and scientific journals that publish the results of research. Even in the case of zoological societies with extensive traditions, any guidelines developed on the use of invasive methodologies are based on learning through trial and error. Therefore, the feedback from researchers is key to perfecting the protocols to reduce risk and trauma for the animals under study, and their population, if endangered. But this does not imply unrestricted freedom to undertake novel interventions that have not been foreseen in ethical protocols.

In the case of SOLAMAC, its Statute establishes as an obligation for its members to ensure compliance with the objectives and ethical norms (Article 8) and even establishes the non-compliance with statutes and ethical norms as a cause of expulsion from the society (Article 11). However, ethical guidelines have not yet been developed. Although in the framework of SOLAMAC an Ethics Committee is foreseen, the Terms of Reference to guide the Committee's work and decisions have not yet been defined either. This is a relevant topic for a relatively young professional society where many of its members are junior scientists at the onset of their research careers. Therefore, our call to SOLAMAC is to fill this gap which should help to consolidate our professional society. This is linked to an aspect that worries us because it occurs with alarming frequency in our jurisdictions: the use of different standards for research than those applied in countries with more stringent evaluation processes. Although these problems are largely due to weaknesses in the legal and institutional frameworks existing in many countries in Latin America, researchers must ethically assume their responsibility and always apply the highest known standards. This is where professional societies such as SOLAMAC have an important role to play as an advisory institution specialized in aquatic mammals, guiding both researchers and national authorities who must issue permits for invasive research when they do not have sufficient expertise or information to assess the risks.

This communication intends to promote the discussion within SOLAMAC about the ethical aspects of invasive research of aquatic mammals in Latin American countries. Defining criteria to establish the acceptable limits of interventions and the minimum requirements for the care and well-being of the studied animals will be a great advance and an important humanistic and academic contribution of our society. We consider that the following aspects should be taken into account as a starting point to define specific ethical guidelines within the framework of SOLAMAC.

- All invasive research on aquatic mammals should have the endorsement of an independent ethics committee prior to the start of the research authorization process, even in jurisdictions where a legal requirement does not exist. It 
is the responsibility of the researcher to deal with it, inside or outside the country, and if necessary, seek guidance.

- Depleted or significantly decreasing populations and Endangered species (sensu IUCN) should not be subject to invasive experimentation nor live-capture. In the case of doubt about the status of a population or species, the precautionary principle should be applied and no invasive experimentation allowed. When dealing with an Endangered species, limited invasive research should only be considered if, with certainty, it would provide an answer to a key question that would help assure the long-term survival of the taxon. Usually, the causes of rapid deterioration are related to human activities such as fishing or habitat degradation, therefore the research on these species/populations should preferentially be oriented to document and address the root causes. Scientific research must not add additional anthropogenic pressure.

- A balance is required between costs (risk of causing injury, suffering or death) and the potential benefit obtained (key information for management) and these should be carefully evaluated. Research that interferes with live animals should respond to the need to generate new knowledge that is vital for the survival of a species or population, all the more so if the taxon has a status of vulnerability or threat.

- Minimize the number of animals subjected to invasive procedures. The need for a statistically representative sample can put a lot of pressure on small populations that are already being subjected to different sources of stress and threats of anthropogenic origin. Researchers should assess the need for intervention based on existing information from other populations of the species, related species of the same genus, or species living in similar habitats.

- Consider designating duly trained personnel with confirmed professional expertise to guarantee that the procedures are carried out under internationally accepted protocols, respecting the current legislation and the conditions under which the permits were issued. In addition to the basic biological parameters of the species, researchers must be familiar with key demographic and ecological aspects of the population in which they are trying to intervene.

- Capture and handling of aquatic mammals demand even more expertise from researchers and appropriate veterinary care. Only in extreme cases, such as when the life of the animals depends on it, should the capture of wild cetaceans be allowed for rehabilitation and research purposes. In the case of pinnipeds and manatees (sirenians), the capture of specimens should be limited in number, kept as short as possible and monitored. In either case, multidisciplinary research teams with the necessary experience and infrastructure must be available.

- Compliance with national, regional, and local regulations (for example in the case of highly sensitive areas) should be demonstrated before invasive research is to be conducted. Provide authorities detailed information on the project design, sampling protocols, results of similar work carried out elsewhere, risk-benefit analysis on the methodology, and mitigation measures that will be used to safeguard the safety and well-being of the studied animals.

- Duly inform the authorities and the scientific community of unexpected issues that arose during the study. This can help refine protocols and reduce the risk to animals in future studies.
- Share and inform about the research work to local communities where the invasive research is carried out, explaining the goals, the methodology, the risks to the animals, and the measures taken to mitigate it. Ideally, local people should be involved in all phases of the project, and in particular the fieldwork component. When ancestral traditions collide with research or conservation strategies, efforts should be made looking for a common understanding of how sociocultural and ecological issues can be integrated.

- If a significant public opposition arises, especially locally, the invasive experimentation or live-capture project should be postponed, and if the opposition persists, canceled.

In conclusion, researchers who work with live aquatic mammals have a great responsibility towards their peers, the public, and authorities about the way they treat the study animals. Lack of transparency can lead to misunderstandings and mistrust from colleagues, promotors, and society to the detriment of the conservation of these species and complications for the scientists involved. For this reason, we reiterate the need for SOLAMAC to have a code of conduct for its members and guidelines for invasive studies that can be shared with institutions, authorities, and managers.

\section{References}

Andrews, R.D., Baird, R.W., Calambokidis, J. Goertz, C.E.C., Gulland, F.M.D., Heide-Jørgensen, M.P., Hooker, S.K., Johnson, M., Mate, B., Mitani, Y., Nowacek, D.P., Owen, K., Quakenbush, L.T., Raverty, S., Robbins, J., Schorr, G.S., Shpak, O.V., Townsend Jr, F.I., Uhart, M.; Wells, R.S. and Zerbini, A.N. (2019) Best practice guidelines for cetacean tagging. Journal of Cetacean Research and Management 20: 27-66.

Block, B.A., Jonsen, I.D., Jorgensen, S.J., Winship , A.J., Shaffer, S.A., Bograd , S.J., Hazen, E.L., Foley, D.G., Breed, G.A., Harrison, A-L., Ganong, J.E., Swithenbank, A., Castleton, M., Dewar, H., Mate, B.R., Shillinger, G.L., Schaefer, K.M., Benson, S.R., Weise, M.J., Henry, R.W. and Costa, D.P. (2011) Tracking apex marine predators movements in a dynamic ocean. Nature 475(7354): 86-90. https://doi.org/10.1038/nature10082

Boisseau, O., McGarry, T., Stephenson, S., Compton, R., Cucknell, A.C., Ryan, C., McLanaghan, R. and Moscrop, A. (2021) Minke whales avoid a $15 \mathrm{kHz}$ acoustic deterrent device. Marine Ecology Progress Series. https://doi.org/10.3354/meps13690

Collins, T. (2015) Re-assessment of the conservation status of the Atlantic humpback dolphin Sousa teuszii (Kükenthal, 1892), using the IUCN Red List Criteria. Pages 47-77 in Jefferson, T.A. and Curry, B.E. (eds) Advances in Marine Biology, vol. 72. Academic Press, Oxford.

Christiansen, F., Rojano-Doñate, L., Madsen, P.T. and Bejder, L. (2016) Noise levels of multi-rotor Unmanned Aerial Vehicles with implications for potential underwater impacts on marine mammals. Frontiers in Marine Science 3: 277.

https://doi.org/10.3389/fmars.2016.00277

Erbe, C., Dunlop, R. and Dolman, S. (2018) Effects of noise on marine mammals. Pages 277-309 in Slabbekoorn, H., Dooling, R.J., Popper, A.N. and Fay, R.R. (eds) Effects of Anthropogenic Noise on Animals. Springer, New York, NY.

Félix, F. (2021) Impacts of fishing entanglement on the bottlenose dolphin society in the Gulf of Guayaquil, Ecuador. Aquatic 
Mammals 47(2): 127-134

https://doi.org/10.1578/AM.47.2.2021.127

García-Cegarra, A.M., Malebran, M., Gatica, C. and Van Waerebeek, K. (2021) Antofagasta Region in northern Chile, a potential nursing ground for the southern right whale Eubalaena australis. Latin American Journal of Aquatic Mammals 16(1) (this issue). https://doi.org/10.5597/lajam00270

Gonzalez-Socoloske, D. and Olivera-Gomez, L.D. (2012) Gentle giants in dark waters: Using side-scan sonar for manatee research. The Open Remote Sensing Journal 5: 1-14. https://doi.org/10.2174/1875413901205010001

Hastie, G.D., Wu, G-M., Moss, S., Jepp, P., MacAulay, J., Lee, A., Sparling, C.E., Evers, C. and Gillespie, D. (2019) Automated detection and tracking of marine mammals: A novel sonar tool for monitoring effects of marine industry. Aquatic Conservation: Marine and Freshwater Ecosystems 29(S1): 119-130.

https://doi.org/10.1002/aqc.3103

Jaramillo-Legorreta, A.M., Cárdenas-Hinojosa, G., Nieto-García, E., Rojas-Bracho, L., Thomas, L., Ver Hoef, J.M., Moore, J., Taylor, B., Barlow, J. and Tregenza, N. (2019) Decline towards extinction of Mexico's vaquita porpoise (Phocoena sinus). Royal Society Open Science 6: 190598.

https://doi.org/10.1098/rsos.190598

Jefferson, T. and Curry, B.E. (eds) (2016) Humpback dolphins (Sousa spp.): Current status and conservation, Part 2. Advances in Marine Biology volume 73. Elsevier, Amsterdam. 362 pp.

Macfarlane, N.B.W. (2015) Tagging wild cetaceans: investigating the balance between more and less invasive techniques. M.Sc. Thesis. Massachusetts Institute of Technology, Boston. $62 \mathrm{pp}$.

Mclntyre, T. (2014) Trends in tagging of marine mammals: a review of marine mammal biologging studies. African Journal of Marine Science 36(4): 409-422.

https://doi.org/10.2989/1814232X.2014.976655

Nowacek, D.P., Christiansen, F., Bejder, L., Goldbogen, J.A. and Friedlander, A.S. (2016) Studying cetacean behaviour: new technological approaches and conservation applications. Animal Behaviour 120: 235-244.

https://doi.org/10.1016/j.anbehav.2016.07.019

Pan, W., Lu, A. and Long, Y. (2013) The White Dolphins of Qinzhou. Peking University Press. ISBN: 978-7-301-23011-4/Q·0140.

Papastavrou, V., Leaper, R. and Lavigne, D. (2017) Why management decisions involving marine mammals should include animal welfare. Marine Policy 79: 19-24.

https://doi.org/10.1016/j.marpol.2017.02.001

Richardson, W.J. and Würsig, B. (1997) Influences of manmade noise and other human actions on cetacean behaviour. Marine and Freshwater Behavioral Physiology 29: 183-209.

https://doi.org/10.1080/10236249709379006

Richardson, W.J., Miller, G.W. and Greene, C.R. (1999) Displacement of migrating bowhead whales by sounds from seismic surveys in shallow waters of the Beaufort Sea. Journal of the Acoustical Society of America 106: 2281.

https://doi.org/10.1121/1.427801

Robbins, J., Zerbini, A.N., Gales, N., Gulland, F.M.D., Double, M., Clapham, P., Andrews-Goff, V., Kennedy, A.S., Landry, S., Mattila, D.K. and Tackaberry, J. (2013) Satellite tag effectiveness and impacts on large whales: preliminary results of a case study with Gulf of Maine humpback whales. Report SC/65a/SHO5 presented to the International Whaling Commission Scientific
Committee, Jeju, Korea, 3-15 June. [Available from the Office of the International Whaling Commission, The Red House, 135 Station Road, Impington, Cambridge, Cambridgeshire CB4 9NP, UK, $<$ http://iwcoffice.org/>].

Van Bressem, M-F., Burville, B., Sharpe, M., Berggren, P. and Van Waerebeek, K. (2018) Visual health assessment of whitebeaked dolphins off the coast of Northumberland, North Sea, using underwater photography. Marine Mammal Science 34(4): 1119-1133. https://doi.org/10.1111/mms.12501

Van Waerebeek, K., Barnett, L., Camara, A., Cham, A., Diallo, M., Djiba, A., Jallow, A.O., Ndiaye, E., Samba Ould Bilal, A.O. and Bamy, I.L. (2004) Distribution, status and biology of the Atlantic humpback dolphin Sousa teuszii (Kükenthal, 1892). Aquatic Mammals 30(1): 56-83.

https://doi.org/10.1578/AM.30.1.2004.56

Van Waerebeek, K., Uwagbae, M., Segniagbeto, G., Bamy, I.L., and Ayissi, I. (2017) New records of Atlantic humpback dolphin (Sousa teuszii) in Guinea, Nigeria, Cameroon and Togo underscore fisheries pressure and generalised marine bushmeat demand. Revue d'Ecologie (Terre et Vie) 72(2): 192-205.

http://documents.irevues.inist.fr/handle/2042/62079

Walker, K.A., Trites, A.W., Haulena, M. and Weary, D.M. (2012) A review of the effects of different marking and tagging techniques on marine mammals. Wildlife Research 39: 15-30. https://doi.org/10.1071/WR10177

Wang, K., Wang, D., Zhang, X., Pfluger, A. and Barrett, L. (2006) Range-wide Yangtze freshwater dolphin expedition: The last chance to see Baiji? Environmental Science and Pollution Research 13(6): 418-424.

https://doi.org/10.1065/espr2006.10.350

Weir, C., Van Waerebeek, K., Jefferson, T.A. and Collins, T. (2011) West Africa's Atlantic humpback dolphin: endemic, enigmatic and soon Endangered? African Zoology 46(1): 1-17.

https://hdl.handle.net/10520/EJC18185

Whitehead, H., Rendell, L., Osborne, R.W. and Würsig, B. (2004) Culture and conservation of non-humans with reference to whales and dolphins: review and new directions. Biological Conservation 120(3): 427-437.

http://doi.org/10.1016/j.biocon.2004.03.017

Whitehead, H., Vachon, F. and Frasier, T.R. (2017) Cultural hitchhiking in the matrilineal whales. Behavior Genetics 47: 324-334.

https://doi.org/10.1007/s10519-017-9840-8

Wilson, B., Porter, L., Gordon, J., Hammond, J., Hodgins, N., Wei, L., Lin, J., Lusseau, D., Tsang, A., Van Waerebeek, K. and Wu, Y.P. (2008) A decade of management plans, conservation initiatives and protective legislation for Chinese white dolphin (Sousa chinensis): An assessment of progress and recommendations for future management strategies in the Pearl River Estuary, China. Workshop Report presented to WWF Hong Kong, 7-11 April 2008, Hong Kong. [Available at https://www.researchgate. net/publication/278037321]

Zhang, P., Sun, N., Yao Z., and Zhang, X. (2012) Historical and current records of aquarium cetaceans in China. Zoo Biology 31: 336-349. https://doi.org/10.1002/zoo.20400 